\title{
Współczynnik plonowania odmian ziemniaka uprawianych w dwóch systemach produkcji
}

\author{
Harvest index of potato cultivars growing under two crop production systems
}

\section{Krystyna Zarzyńska ${ }^{\bowtie}$, Dominika Boguszewska-Mańkowska, Piotr Barbaś}

Instytut Hodowli i Aklimatyzacji Roślin — Państwowy Instytut Badawczy, Radzików, Zakład Agromomii Ziemniaka, Jadwisin

$\bowtie$ e-mail: k.zarzynska@ihar.edu.pl

\begin{abstract}
Badania przeprowadzono w latach 2014-2016 w dwóch miejscowościach w Polsce: Stacja Doświadczalna IUNG w Osinach na glebie kompleksu żytniego bardzo dobrego i w Instytucie Hodowli i Aklimatyzacji Roślin w Jadwisinie na glebie kompleksu żytniego słabego. Ziemniaki uprawiano w obu miejscowościach w dwóch systemach produkcji - ekologicznym i integrowanym. W badaniach oceniano 6 odmian ziemniaka należących do dwóch grup wczesności - wczesnych i średnio wczesnych. W pełni rozwoju roślin określano ich masę nadziemną, a w czasie zbioru wielkość plonu. Współczynnik plonowania określano jako udział masy bulw w całej masie nadziemnej i podziemnej. Stwierdzono, że na współczynnik plonowania roślin ziemniaka największy wpływ miał czynnik odmianowy. System produkcji i warunki glebowo-klimatyczne nie wpłynęły na wielkość tego wskaźnika. Zakres współczynnika plonowania był szeroki i wynosił w zależności od odmiany, warunków środowiska i systemu produkcji od 50 do $83 \%$, co oznacza, że w sprzyjających warunkach aż 83\% asymilatów może być ulokowane w bulwach
\end{abstract}

Słowa kluczowe: ziemniak, odmiana, system produkcji, współczynnik plonowania

The research was carried out in 2014-2016 in two sites in Poland: Experimental Station IUNG in Osiny on the heavier soil and in the Plant Breeding and Acclimatization Institute in Jadwisin on the lighter soil. Potatoes were grown in both locations in two production systems, i.e. organic and integrated. The studies evaluated 6 potato cultivars belonging to two groups of earliness: early and mid early. The aboveground mass was determined in the fullness of plant development, and the crop yield during the harvest. The harvest index - HI was defined as the share of tuber mass in the total above and underground mass. It was found that the harvest index yield factor of potato plants was the most influenced by the varietal factor. The production system and soil and climatic conditions did not affect the size of this indicator. The range of this indicator was wide and ranged from 50 to $83 \%$, which means that under favorable conditions up to $83 \%$ of assimilates can be located in tubers.

Key words: potato, cultivar, harvest index, crop production system

\section{Wstęp}

Rośliny rosnące w sprzyjających środowiskach, wolne od szkodników i chorób, z wystarczającą ilością wody i składników odżywczych wytwarzają większą masę nadziemną i uzyskują większe plony niż rośliny uprawiane pod wpływem jakiegokolwiek stresu. Zarządzanie wzrostem roślin w celu zmaksymalizowania wydajności, przy jednoczesnej minimalizacji wody, nawozów, pestycydów i innych środków produkcji jest głównym celem w komercyjnej produkcji roślinnej. Ważną sprawą jest prawidłowy rozdział asymilatów między częścią nadziemną rośliny, a w przypadku ziemniaka bulwami, ponieważ nadmierny ich przepływ do jednej lub drugiej części może prowadzić do zmniejszenia wydajności i/lub jakości bulw. Dlatego istotne jest, aby związek między wzrostem listowia i bulw był utrzymywany w sposób, który maksymalizuje wydajność i jakość bulw (Navarre i Pavek, 2014).

Termin index plonowania ( $\mathrm{z}$ ang. harvest index - HI) wprowadził Donald (1962), aby opisać relację dotyczącą przepływu asymilatów u pszenicy jako stosunek wskazujący procent całkowitej masy rośliny pochodzący $\mathrm{z}$ plonu ziarna w stosunku do plonu słomy. Uważał, że odmiany pszenicy, które wytworzyły stosunkowo wysoki plon ziarna w porównaniu do plonu słomy, były bardziej fotosyntetycznie wydajne niż te, w których plon słomy był dominujący. Współczynnik plonowania można wykorzystać jako narzędzie dla każdej rośliny do opisania tych zależności.

W przypadku ziemniaków harvest index oznacza udział bulw jako procent całkowitej biomasy roślinnej (bulwy plus masa nadziemna rośliny), stąd np. HI = 0,50 wskazuje, że $50 \%$ całkowitej świeżej masy rośliny to bulwy. HI ziemniaka wzrasta w ciągu całego sezonu wegetacyjnego, osiągając $\mathrm{w}$ pełni dojrzałości wartość 1.

Wskaźnik ten zależy od wielu czynników, z których główne to: cechy odmianowe, warunki wegetacji, takie jak: fotoperiod, temperatura powietrza, woda, nawożenie azotem (Belanger i in., 2001; Cutter, 1992; Dwelle, 1985; Firman 
i Allen, 1988; Gawrońska i in., 1990; Mazurczyk i Lis, 2000). Ziemniak charakteryzuje się jednym z największych wskaźników plonowania. Nowoczesne odmiany ziemniaka uprawiane w klimacie umiarkowanym przy sprzyjających warunkach agrometeorologicznych mogą osiągnąć wskaźnik w zakresie od 0,70 do 0,85 (Belanger i in., 2001; Beukema i Zaag van der 1990; Firman i Allen, 1989; Mazurczyk W., Lis 2000). W literaturze można znaleźć nawet wartość 0,90 (Belanger i in., 2001; Mazurczyk, Lis, 2000), co oznacza, że $90 \%$ biomasy gromadzi się w bulwach. Dla porównania HI zbóż waha się od 0,4 do 0,6 (Hay, 2008).

Jednym z czynników różnicujących wielkość tego współczynnika może być system produkcji, w jakim uprawiane są rośliny, dlatego też celem pracy była ocena wielkości współczynnika plonowania sześciu odmian ziemniaka uprawianych $\mathrm{w}$ dwóch systemach produkcjiekologicznym i integrowanym, w zróżnicowanych warunkach klimatyczno-glebowych (dwie miejscowości) w Polsce.

\section{Material i Metody}

Badania prowadzone były w latach 2014 2016 w dwóch miejscowościach w Polsce: Stacja Doświadczalna IUNG w Osinach $\left(51,4667^{\circ} \mathrm{N}\right.$, $\left.22.0667^{\circ} \mathrm{E}\right)$ na glebie wytworzonej $\mathrm{z}$ piasków gliniastych mocnych (kompleks glebowy żytni bardzo dobry) i w Instytucie Hodowli i Aklimatyzacji Roślin, Oddział w Jadwisinie $52^{\circ} 4500^{\prime \prime} \mathrm{N} 21633^{\circ} \mathrm{E}$ ) na glebie wytworzonej z piasków gliniastych lekkich (kompleks glebowy żytni słaby).

W obu miejscowościach ziemniaki uprawiane były w 2 systemach produkcji, tj. ekologicznym i integrowanym. W każdym systemie stosowano różne technologie i płodozmian dostosowany do warunków glebowych.

- Płodozmian stosowany w systemie ekologicznym na glebie mocniejszej: ziemniak jęczmień z wsiewka koniczyny czerwonej koniczyna czerwona $\mathrm{z}$ trawami - koniczyna czerwona $\mathrm{z}$ trawami + międzyplon pszenica ozima.

- Płodozmian stosowany $\mathrm{w}$ systemie integrowanym na glebie mocniejszej: ziemniak jęczmień - peluszka na nasiona - pszenica ozima + międzyplon.

- Płodozmian stosowany w systemie ekologicznym na glebie lżejszej: ziemniak jęczmień jary - mieszanka peluszki z grochem pastewnym i żytem jarym mieszanka łubinu żółtego i owsa - żyto z wsiewką seradeli.

- Płodozmian stosowany $\mathrm{w}$ systemie integrowanym na glebie lżejszej: ziemniaki pszenica jara - pszenica ozima — łubin.

Oba systemy produkcji różniły się nawożeniem, sposobem zwalczania chwastów oraz metodami ochrony przed chorobami i szkodnikami (tab. 1).

Tabela 1

Table 1

Agrotechnika stosowana w systemie ekologicznym i integrowanym w 2 miejscowościach Agronomic inputs in organic and integrated systems in 2 sites

\begin{tabular}{|c|c|c|c|c|}
\hline \multicolumn{5}{|c|}{ Agronomic inputs in organic and integrated systems in 2 sites } \\
\hline \multirow{2}{*}{$\begin{array}{l}\text { Zabiegi agrotechniczne } \\
\text { Agronomic inputs }\end{array}$} & \multicolumn{2}{|c|}{ Jadwisin } & \multicolumn{2}{|c|}{ Osiny } \\
\hline & $\begin{array}{l}\text { system ekologiczny } \\
\text { organic system }\end{array}$ & $\begin{array}{c}\text { system integrowany } \\
\text { integrated system }\end{array}$ & $\begin{array}{l}\text { system ekologiczny } \\
\text { organic system }\end{array}$ & $\begin{array}{c}\text { system integrowany } \\
\text { integrated system }\end{array}$ \\
\hline $\begin{array}{l}\text { Nawożenie } \\
\text { Fertilization }\end{array}$ & $\begin{array}{l}\text { obornik }+ \text { gorczyca } \\
\text { międzyplon } \\
\text { manure }-28 \mathrm{t} \cdot \mathrm{ha}^{-1}+ \\
\text { mustard as a catch crop }\end{array}$ & 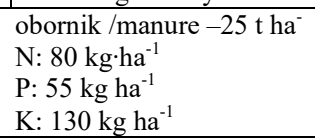 & $\begin{array}{l}\text { kompost } \\
\text { compost }-30 \mathrm{t} \cdot \mathrm{ha}^{-1}+\text { catch } \\
\text { crop }\end{array}$ & $\begin{array}{l}\text { obornik /manure }-25 \mathrm{tha}^{-1} \\
\mathrm{~N}: 75 \mathrm{~kg} \mathrm{ha}^{-1} \\
\mathrm{P}: 60 \mathrm{~kg} \mathrm{ha}^{-1} \\
\mathrm{~K}: 105 \mathrm{~kg} \mathrm{ha}^{-1}\end{array}$ \\
\hline $\begin{array}{l}\text { Zwalczanie chwastów } \\
\text { Weed control }\end{array}$ & $\begin{array}{l}\text { tylko mechaniczne } \\
\text { only mechanical tillage }\end{array}$ & $\begin{array}{l}\text { mechaniczne }+ \text { herbicydy } \\
\text { mechanical tillage }+ \\
\text { herbicides }\end{array}$ & $\begin{array}{l}\text { tylko mechaniczne } \\
\text { only mechanical tillage }\end{array}$ & $\begin{array}{l}\text { mechaniczne }+ \text { herbicydy } \\
\text { mechanical tillage }+ \\
\text { herbicides }\end{array}$ \\
\hline $\begin{array}{l}\text { Zwalczanie stonki } \\
\text { ziemniaczanej } \\
\text { Colorado potato beetle } \\
\text { control }\end{array}$ & $\begin{array}{l}\text { insektycyd biologiczny } \\
\text { biological insecticide } \\
\text { (Bacillus thuringensis) }\end{array}$ & $\begin{array}{l}\text { insektycydy chemiczne } \\
\text { chemical insecticides }\end{array}$ & $\begin{array}{l}\text { insektycyd biologiczny } \\
\text { biological insecticide } \\
\text { (Bacillus thuringiensis }\end{array}$ & $\begin{array}{l}\text { insektycydy chemiczne } \\
\text { chemical insecticides: }\end{array}$ \\
\hline $\begin{array}{l}\text { Zwalczanie zarazy } \\
\text { ziemniaka } \\
\text { Late blight control }\end{array}$ & $\begin{array}{l}\text { fungicydy miedziowe } \\
\text { copper fungicides }\end{array}$ & $\begin{array}{l}\text { fungicydy chemiczne } \\
\text { chemical fungicides }\end{array}$ & $\begin{array}{l}\text { fungicydy miedziowe } \\
\text { copper fungicides }\end{array}$ & $\begin{array}{l}\text { fungicydy chemiczne } \\
\text { chemical fungicides }\end{array}$ \\
\hline
\end{tabular}


Uprawiano 6 odmian ziemniaka $\mathrm{z}$ dwóch grup wczesności o różnej odporności na Phytophthora infestans. Charakterystykę badanych odmian podano w tabeli 2 .

Tabela 2

Table 2

Charakterystyka 6 odmian ziemniaka uprawianych w systemie ekologicznym $i$ integrowanym w 2 miejscowościach w latach 2014-2016

Characteristics of 6 potato cultivars growing under organic and integrated system in 2 sites in years 2014-2016

\begin{tabular}{|c|c|c|}
\hline $\begin{array}{l}\text { Odmiana } \\
\text { Cultivar }\end{array}$ & $\begin{array}{l}\text { Grupa wczesności } \\
\text { Maturity group }\end{array}$ & \begin{tabular}{|c} 
Odporność na \\
Phytophthora infestans \\
Resistance to \\
Phytophthora \\
infestans*
\end{tabular} \\
\hline Cyprian & wczesna - early & 5 \\
\hline Ignacy & wczesna - early & 3 \\
\hline Michalina & wczesna — arly & 3 \\
\hline Jurata & średnio wczesna - mid early & 4 \\
\hline Malaga & średnio wczesna - mid early & 3,5 \\
\hline Oberon & średnio wczesna - mid early & 3,5 \\
\hline
\end{tabular}

Wszystkie odmiany były sadzone $\mathrm{w}$ tym samym czasie około 20 kwietnia w rozstawie 75 $\times 33 \mathrm{~cm}$. W pełni rozwoju roślin w końcu czerwca dla odmian wczesnych i 2 tygodnie później dla odmian średnio wczesnych dokonano pomiarów masy nadziemnej roślin. Rośliny były wykopane, policzone zostały łodygi i zważona została cała masa nadziemna. Pomiary wykonano na 4 roślinach z każdego z 3 powtórzeń, tj. na 12 roślinach z każdej odmiany.

Podczas zbioru ok 10 września oceniono wielkość plonu ze wszystkich poletek z 3 powtórzeń. Index plonowania (HI) obliczano wg wzoru (Navarre i Pavek, 2014):

HI = świeża masa bulw/(masa nadziemna rośliny + świeża masa bulw).

W obliczeniach statystycznych zastosowano analizę wariancji, używając programu ANOVA. Istotność zróżnicowania oceniano testem tStudenta. Charakterystykę warunków pogodowych panujących w obu miejscowościach w trzech latach badań podano w tabeli 3 .

Tabela 3

Table 3

Suma miesięcznych opadów $(O)$ i średnia temperatura miesiąca $(T)$ podczas okresu wegetacji w latach 2014-2016 dla Jadwisina i Osin

Total monthly rainfall $(R)$ and mean monthly temperatures $(T)$ during the vegetative growth period in the years 2014-2016 for Jadwisin and Osiny

\begin{tabular}{|c|c|c|c|c|c|c|c|c|c|c|c|c|c|}
\hline \multirow[b]{2}{*}{$\begin{array}{l}\text { Rok } \\
\text { Year }\end{array}$} & \multirow{2}{*}{$\begin{array}{l}\text { Miejscowość } \\
\text { Place }\end{array}$} & \multicolumn{2}{|c|}{ IV } & \multicolumn{2}{|c|}{$\mathrm{V}$} & \multicolumn{2}{|c|}{ VI } & \multicolumn{2}{|c|}{ VII } & \multicolumn{2}{|c|}{ VIII } & \multicolumn{2}{|c|}{ IX } \\
\hline & & $\begin{array}{c}\mathrm{O} \\
(\mathrm{mm})\end{array}$ & $\begin{array}{c}\mathrm{T} \\
\left({ }^{\circ} \mathrm{C}\right)\end{array}$ & $\begin{array}{c}\mathrm{O} \\
(\mathrm{mm})\end{array}$ & $\begin{array}{c}\mathrm{T} \\
\left({ }^{\circ} \mathrm{C}\right)\end{array}$ & $\begin{array}{c}\mathrm{O} \\
(\mathrm{mm})\end{array}$ & $\begin{array}{c}\mathrm{T} \\
\left({ }^{\circ} \mathrm{C}\right)\end{array}$ & $\begin{array}{c}\mathrm{O} \\
(\mathrm{mm})\end{array}$ & $\begin{array}{c}\mathrm{T} \\
\left({ }^{\circ} \mathrm{C}\right)\end{array}$ & $\begin{array}{c}\mathrm{O} \\
(\mathrm{mm})\end{array}$ & $\begin{array}{c}\mathrm{T} \\
\left({ }^{\circ} \mathrm{C}\right)\end{array}$ & $\begin{array}{c}\mathrm{O} \\
(\mathrm{mm})\end{array}$ & $\begin{array}{c}\mathrm{T} \\
\left({ }^{\circ} \mathrm{C}\right)\end{array}$ \\
\hline \multirow{2}{*}{2014} & Jadwisin & 61,1 & 10,3 & 41,3 & 14,1 & 69,8 & 15,8 & 23,5 & 21,5 & 79,2 & 18,2 & 11,9 & 14,8 \\
\hline & Osiny & 67,5 & 10,2 & 170,5 & 13,4 & 99,4 & 15,7 & 56,2 & 20,6 & 105,5 & 18,4 & 17,8 & 14,5 \\
\hline \multirow{2}{*}{2015} & Jadwisin & 27,8 & 8,3 & 39,5 & 12,9 & 15,4 & 17,5 & 62,3 & 19,6 & 8,6 & 22,5 & 36,6 & 15,1 \\
\hline & Osiny & 29,4 & 8,2 & 108,7 & 12,6 & 29,2 & 16,8 & 52,1 & 19,8 & 4,3 & 22,4 & 40,1 & 15,5 \\
\hline \multirow{2}{*}{2016} & Jadwisin & 92,2 & 15,3 & 85,4 & 18,7 & 103,6 & 19,6 & 61,4 & 18,4 & 9,5 & 15,7 & 92,2 & 15,3 \\
\hline & Osiny & 87,5 & 15,0 & 75,6 & 18,2 & 95,7 & 19,9 & 60,5 & 18,5 & 10,9 & 15,8 & 87,5 & 15,0 \\
\hline
\end{tabular}

\section{Wyniki i Dyskusja}

Przeprowadzona analiza wariancji wykazała istotność zróżnicowania tylko jednego czynnika — odmiany. Pozostałe czynniki: system produkcji, miejsce uprawy i lata badań nie wpłynęły w sposób istotny na wartość współczynnika plonowania. Udowodniono istotność interakcji tylko miejsca uprawy i lat badań (tab. 4).

Tabela 4

Table 4

Istotność badanych parametrów Significance of differences in parameter means

\begin{tabular}{lc}
\multicolumn{1}{c}{$\begin{array}{c}\text { Badany parametr } \\
\text { Tested parameter }\end{array}$} & $\mathrm{p}$ \\
\hline Odmiana - Cultivar & 0,012 \\
System produkcji - Crop production system & n.s \\
Miejscowośc - Place & n.s \\
Lata - Years & n.s \\
Miejscowość $\times$ lata — Place $\times$ years & 0,002 \\
\hline
\end{tabular}

ns. - nieistotne statystycznie

n.s - no statistical differences
W tabeli 5 podano dane dotyczące wielkości masy nadziemnej roślin i plonu bulw z 1 rośliny dla poszczególnych odmian, miejsca uprawy i systemu produkcji. Jak wynika $\mathrm{z}$ przedstawionych danych dla większości przypadków w systemie ekologicznym wartości badanych parametrów były niższe iż $\mathrm{w}$ systemie integrowanym, chociaż zdarzały się sytuacje (szczególnie w Osinach), gdzie zarówno masa nadziemna, jak plon bulw były wyższe w systemie ekologicznym (tab. 5).

Badane odmiany różniły się istotnie wielkością współczynnika plonowania. Zakres wartości tego wskaźnika wahał się w granicach 0,62 do 0,73 . Najniższy wskaźnik uzyskano dla średnio wczesnej odmiany Oberon, najwyższy dla wczesnej odmiany Ignacy (tab. 6). 
Masa nadziemna i plon bulw z 1 rośliny w zależności od odmiany, systemu produkcji i miejscowości (średnio z 3 lat badań)

Aboveground mass and yield from 1 plant in relation to cultivar, crop production system and site of growing (mean of 3 years)

\begin{tabular}{|c|c|c|c|c|}
\hline $\begin{array}{c}\text { Odmiana } \\
\text { Cltivar }\end{array}$ & $\begin{array}{l}\text { Miejscowość } \\
\text { Place } \\
\end{array}$ & $\begin{array}{l}\text { System produkcji } \\
\text { Production system }\end{array}$ & $\begin{array}{c}\text { Masa nadziemna } \\
\text { Abovegrund mass }(\mathrm{g})\end{array}$ & $\begin{array}{c}\text { Plon bulw z } 1 \text { rośliny } \\
\text { Yield }(\mathrm{g})\end{array}$ \\
\hline \multirow{4}{*}{ Cyprian } & \multirow{2}{*}{ Jadwisin } & ekologiczny & 297,2 & 598,0 \\
\hline & & integrowany & 501,7 & 1003,3 \\
\hline & \multirow{2}{*}{ Osiny } & ekologiczny & 258,1 & 500,0 \\
\hline & & integrowany & 204,7 & 684,0 \\
\hline \multirow{4}{*}{ Ignacy } & \multirow{2}{*}{ Jadwisin } & ekologiczny & 292,5 & 738,0 \\
\hline & & integrowany & 509,4 & 1120,0 \\
\hline & \multirow{2}{*}{ Osiny } & ekologiczny & 285,6 & 779,0 \\
\hline & & integrowany & 206,1 & 808,3 \\
\hline \multirow{4}{*}{ Michalina } & \multirow{2}{*}{ Jadwisin } & ekologiczny & 411,1 & 736,3 \\
\hline & & integrowany & 761,7 & 1232,0 \\
\hline & \multirow{2}{*}{ Osiny } & ekologiczny & 369,2 & 671,7 \\
\hline & & integrowany & 369,2 & 671,7 \\
\hline \multirow{4}{*}{ Jurata } & \multirow{2}{*}{ Jadwisin } & ekologiczny & 374,4 & 851,3 \\
\hline & & integrowany & 872,8 & 1039,6 \\
\hline & \multirow{2}{*}{ Osiny } & ekologiczny & 271,1 & 604,0 \\
\hline & & integrowany & 386,4 & 711,3 \\
\hline \multirow{4}{*}{ Malaga } & \multirow{2}{*}{ Jadwisin } & ekologiczny & 279,2 & 713,4 \\
\hline & & integrowany & 726,7 & 1104,0 \\
\hline & \multirow{2}{*}{ Osiny } & ekologiczny & 214,5 & 550,7 \\
\hline & & integrowany & 273,6 & 705,7 \\
\hline \multirow{4}{*}{ Oberon } & \multirow{2}{*}{ Jadwisin } & ekologiczny & 376,7 & 726,3 \\
\hline & & integrowany & 652,8 & 1023,6 \\
\hline & \multirow{2}{*}{ Osiny } & ekologiczny & 280,9 & 377,0 \\
\hline & & integrowany & 342,0 & 486 \\
\hline
\end{tabular}

Tabela 6

Table 6

Wpływ odmiany na wielkość współczynnika plonowania HI (średnio dla miejsca uprawy, systemu produkcji i lat badań)

Influence of cultivar on HI (mean for site, production system and years)

\begin{tabular}{c|c}
\hline Odmiana-Cultivar & HI \\
\hline Oberon & $0,62 \mathrm{a}$ \\
Michalina & $0,65 \mathrm{a} \mathrm{b}$ \\
Jurata & $0,66 \mathrm{a} \mathrm{b}$ \\
Malaga & $0,67 \mathrm{a} \mathrm{b}$ \\
Cyprian & $0,70 \mathrm{a} \mathrm{b}$ \\
Ignacy & $0,73 \mathrm{~b}$ \\
\hline
\end{tabular}

$\mathrm{a}, \mathrm{b}$ - wyniki oznaczone różnymi literami są statystycznie istotne $\mathrm{a}, \mathrm{b}$ - statistically different groups

Średnio dla wszystkich odmian wskaźnik plonowania wyniósł 0,67 , co oznacza, że $67 \%$ asymilatów zostało ulokowane w bulwach. Spośród 6 badanych odmian, 3 zaliczono do grupy odmian wczesnych i trzy do średnio wczesnych. Z obserwacji i wcześniejszych badań wiadomo, że model rozwoju wczesnych i późniejszych odmian ziemniaka jest nieco inny (Cutter, 1992; Szutkowska, 2009; Zarzyńska i Goliszewski, 2005). Wczesne odmiany na ogół charakteryzują się niższą masą nadziemną niż późniejsze, ale także dają niższy plon bulw, stąd udział bulw w całkowitej biomasie często pozostaje na podobnym poziomie, jednak $\mathrm{u}$ wysokoplennych odmian wcześniejszych współ- czynnik ten jest na ogół wyższy. W prezentowanych badaniach dwa najwyższe współczynniki uzyskano dla odmian wczesnych. Podobne zależności uzyskała Zarzyńska i in. (2016) oceniając udział masy użytkowej i nieużytkowej w całej biomasie rośliny.

System produkcji nie wpłynął na wielkość współczynnika plonowania. Zarówno w systemie ekologicznym, jak i integrowanym wielkość tego wskaźnika wynosiła 0,67 (tab. 7). W literaturze niewiele jest doniesień dotyczących wpływu systemu produkcji na wielkość współczynnika plonowania. $W$ badaniach Zarzyńskiej $i$ in. (2016) stwierdzono, że największy wpływ na udział bulw w całej biomasie rośliny miał czynnik odmianowy i miejsce uprawy. Sam system produkcji nie różnicował $\mathrm{w}$ sposób istotny tego wskaźnika. Większość badaczy najczęściej oceniało wielkość HI w odniesieniu do plantacji konwencjonalnych, z różnymi poziomami nawożenia (Belanger i in., 2001; Firman i Allen 1988; Mazurczyk i in., 2009; Rosen i Bierman, 2012; Vos, 1997). Według tych doniesień wskaźnik ten maleje wraz ze wzrostem nawożenia dawkami azotu (Belanger i in., 2001; Mazurczyk i in., 2009; Rosen i Bierman, 2012; Vos, 1997). W badaniach własnych nie zaobserwowano takiego związku. Również Mazurczyk i in. 
(2000) nie potwierdzili takiej zależności. W niniejszej pracy nie porównywano wprawdzie różnych dawek azotu, lecz różne systemy produkcji, ale wiadomo że w systemie ekologicznym stosowano tylko nawozy naturalne, podczas gdy w systemie integrowanym dodatkowo też nawożenie mineralne.

Lokalizacje uprawy (Osiny, Jadwisin) nie różnicowały w sposób istotny wielkości wskaźnika HI. Brak istotnego wpływu, głównie jakości gleby na wielkość HI może być zaskakujący. Wiadomo jest, że na glebie cięższej uzyskiwane plony są wyższe niż na glebie lżejszej. Wytłumaczeniem może być fakt, że rozwój części nadziemnej roślin jest również większy, co ostatecznie nie zmienia w znaczący sposób wielkości wskaźnika plonowania.

Analiza wariancji wykazała istotność współdziałania miejsca uprawy $\mathrm{z}$ latami badań. $\mathrm{W}$ roku 2014 istotnie wyższy współczynnik plonowania uzyskano w Osinach, a roku 2015 w Jadwisinie (tab. 7).

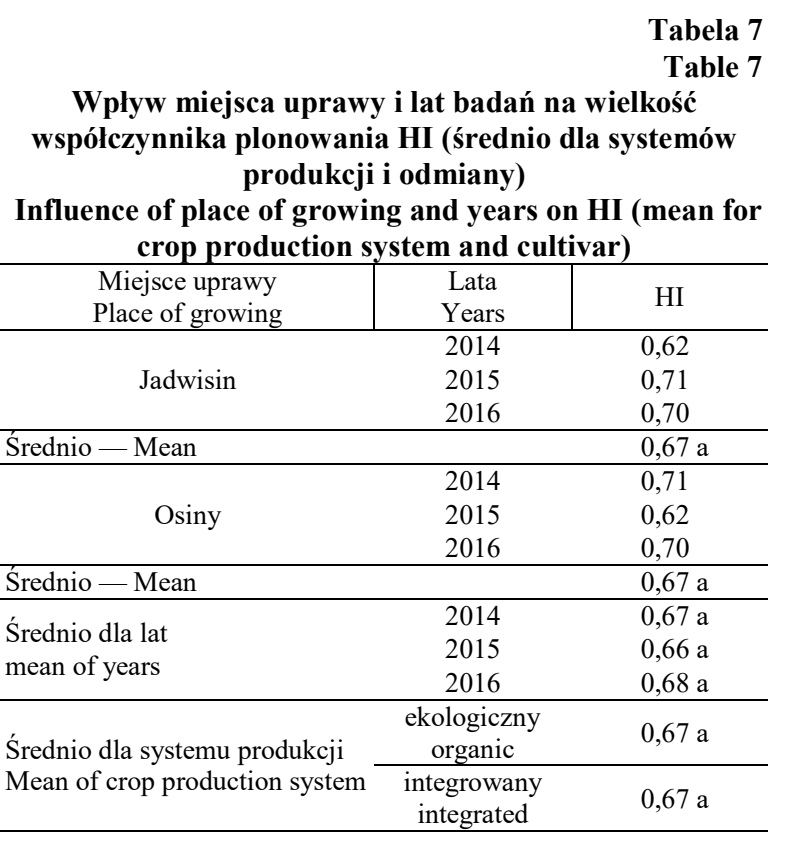

Lata badań (warunki pogodowe w okresie wegetacji) nie wpłynęły $\mathrm{w}$ sposób istotny na wielkość współczynnika plonowania. Nieco wyższy wskaźnik uzyskano w 2016 roku o najlepszym rozkładzie opadów w okresie wegetacji, najniższy zaś $\mathrm{w}$ roku 2015 o najniższym poziomie i najgorszym rozkładzie opadów (tab. 7).

Według danych literaturowych i badań własnych plonowanie ziemniaków w systemie ekologicznym jest od 10 do nawet $70 \%$ niższe niż systemie konwencjonalnym i o $20-30 \%$ niższe niż $\mathrm{w}$ integrowanym (Kuś i Stalenga
1998, Zarzyńska i Goliszewski 2005, Zarzyńska 2013). Uzależnione jest to głównie od warunków atmosferycznych panujących $w$ okresie wegetacji. Zarzyńska i Pietraszko (2015) wykazały, że w bardzo niekorzystnym pod względem rozkładu opadów roku 2013 plony ziemniaków w systemie ekologicznym były aż o $70 \%$ niższe niż w konwencjonalnym. Warunki klimatyczne, a głównie ilość i rozkład opadów są szczególnie istotne $\mathrm{w}$ przypadku uprawy ziemniaka. Można przypuszczać, że zróżnicowane warunki atmosferyczne powinny wpływać również na rozdział asymilatów w roślinie, tj. różnicować współczynnik plonowania. W naszych badaniach takie zjawisko nie miało miejsca.

Zakres wielkości współczynnika plonowania uzyskany w okresie trzech lat dla sześciu odmian ziemniaka, dwóch systemów produkcji i dwóch miejscowości wynosił od 0,50 do 0,83 , co oznacza że w pierwszym przypadku tylko $50 \%$ asymilatów skumulowało się $\mathrm{w}$ bulwach $\mathrm{i}$ aż $83 \%$ w drugim przypadku Najniższy wynik uzyskano dla odmiany Oberon uprawianej w systemie ekologicznym w Osiach w 2016 roku, najwyższy zaś dla odmiany Ignacy uprawianej w systemie integrowanym również w Osinach w 2014 roku.

Średnia wielkość współczynnika plonowania uzyskana dla wszystkich kombinacji wyniosła 0,67 , co daje porównywalny wynik dla roślin ziemniaka podawany przez Belangera i in. 2001.

\section{Wnioski}

1. Na współczynnik plonowania roślin ziemniaka największy wpływ miał czynnik odmianowy. System produkcji i warunki glebowo-klimatyczne nie wpłynęły na wielkość tego wskaźnika.

2. Stwierdzono, że zakres współczynnika plonowania był szeroki i wynosił w zależności od odmiany, systemu produkcji i warunków środowiska od 50 do $83 \%$, co oznacza, że w sprzyjających warunkach aż $83 \%$ asymilatów może być ulokowane w bulwach.

\section{Literatura}

Belanger G., Walsh J. R., Richards J. E., Milburn P. H., Ziadi N. 2001. Tuber growth and biomass partitioning of two potato cultivars grown under different $\mathrm{N}$ fertilization rates with and without irrigation. Am. J. Pot. Res. 78: $109-117$.

Carrie H., Wohleb N., Knowles R., Pavek M., 2014. Plant growth and development. In: The Potato. Botany, Production and Uses. Nawarre R., Pavek M. (ed.), 64 -83 . 
Cutter E. G. 1992. Structure and development of the potato plant. In: Harris P. M. (ed.). The potato crop. Chapmanand Hall, London: $65-161$.

Donald C. M. 1962. In search of yield. Journal of the Australian Institute of Agricultural Science 28: 171178.

Dwelle R. B. 1985. Photosynthesis and assimilate partitioning. In: Li, P. H. (ed.) Potato Physiology. Academic Press, Orlando, Florida: $35-58$.

Firman D. M., Allen E. J. 1989. Relationship between light interception, ground cover and leaf area index in potatoes. J. Agric. Sci.113: 355 - 359.

Firman D. M., Allen E. J. 1988. Field measurements of photosynthetic rate of potatoes grown under different amounts of nitrogen fertilizer. J. Agric. Sci. 11: $151-$ 163.

Gawrońska H., Dwelle R. B., Pavek J. J. 1990. Partitioning of photoassimilates by potato plants (Solanum tuberosum L.) as influence by irradiance. Am. Potato J. 67: $163-176$.

Hay R. K. M. 2008. Harvest index: A review of its use in plant breeding and crop physiology. Annales of Applied Biology 126, 10: 197 - 216.

Jefferis R. A., MacKerron D. K. L. 1989. Radiation interception and growth of irrigated and droughted potato (Solanum tuberosum). Field Crop Res. 22: 101 -102 .

Kuś J., Stalenga J. 1998. Plonowanie kilku odmian ziemniaka uprawianych $\mathrm{w}$ systemach integrowanym i ekologicznym. Rocz. AR Poznań, 307, Rol. 52, 1: 169 -174 .

Mazurczyk W., Lis B. 2000. Wpływ deficytu i nadmiaru azotu w roślinie ziemniaka na gromadzenie i dystrybucję biomasy. Acta Agrobot. 53, 47 - 56.
Mazurczyk W., Wierzbicka A., Trawczyński C. 2009. Harvest index of potato crop grown under different nitrogen and water supply. Acta Sci. Pol., Agricultura 8 (4): $15-21$.

Navarre R., Pavek M. 2014. Potato. Botany, Production and Uses.: $370 \mathrm{pp}$.

Rosen C. J., Bierman P. M. 2012. Potato yield and tuber set as affected by phosphorus fertilization. Am. Potato J. 85: $110-120$.

Szutkowska M. 2009. Rozwój roślin, a plonowanie bardzo wczesnych odmian ziemniaka. Ziemniak Polski 1: 19 -23 .

Victorio R. G., Moreno U., Bleck Jr. C. C. 1986. Growth, partitioning and harvest index of tuber-bearing solanum genotypes grown in two contrasting Peruvian environments. Plant Physiol. 82: $103-108$.

Vos J. 1997. The nitrogen response of potato (Solanum tuberosum L.) in the field: nitrogen uptake and yield, harvest index and nitrogen concentration. Potato Res. 40: $237-248$.

Zarzyńska K. 2013. Plonowanie ekologicznych plantacji ziemniaka W: Ekologiczna produkcja ziemniaka. Nowacki W. (red.) Wyd. MRiRW: $155-174$.

Zarzyńska K., Goliszewski W. 2005. Różnice w rozwoju roślin ziemniaka uprawianych $\mathrm{w}$ dwóch systemach produkcji: ekologicznym i integrowanym na różnych typach gleb. Biul. IHAR 237/238: 133 - 141.

Zarzyńska K., Goliszewski W., Boguszewska D. 2016. Usable and non-usable biomass of potatoes grown under two crop production systems and different environmental conditions. EJPAU 19(1), \#08.

Zarzyńska K., Pietraszko M. 2015. Influence of different vegetation conditions on development and yield of potato plants growing under organic and conventional systems in Poland. Am. Potato J. 92: 511 — 517. 